\title{
Correction to: Investigating groundwater recharge potential zones using a cross-correlation technique in a part of Deccan Volcanic Province (DVP), Central India
}

\author{
Ajay Kumar Venkatarao ${ }^{1} \cdot$ Nepal Chandra Mondal $^{1,2}\left[\right.$. Shakeel Ahmed ${ }^{3}$ \\ Published online: 20 January 2020 \\ ○) Springer-Verlag GmbH Germany, part of Springer Nature 2020
}

Correction to: Environmental Earth Sciences (2019) 78:704
https://doi.org/10.1007/s12665-019-8712-3

Unfortunately, in the original article the e-mail ids of Ajay Kumar Venkatarao and Shakeel Ahmed were published wrongly.

The correct e-mail ids should be Ajay Kumar Venkatarao (ajay183v@gmail.com) and Shakeel Ahmed (shakeelifcgr@ gmail.com) instead of Ajay Kumar Venkatarao (ajay183v@ gamil.com) and Shakeel Ahmed (shakeelifegr@gamil.com).

Publisher's Note Springer Nature remains neutral with regard to jurisdictional claims in published maps and institutional affiliations.

The original article can be found online at https://doi.org/10.1007/ s12665-019-8712-3.

Nepal Chandra Mondal ncmngri@gmail.com

Ajay Kumar Venkatarao ajay183v@gmail.com

Shakeel Ahmed shakeelifcgr@gmail.com

1 Academy of Scientific and Innovative Research (AcSIR), CSIR-NGRI, Hyderabad, India

2 Earth Process Modeling Group, CSIR-National Geophysical Research Institute, Hyderabad, India

3 Department of Geography, Jamia Millia Islamia, New Delhi, India 